\title{
Identifying Specific Beliefs to Target to Improve Restaurant Employees’ Intentions for Performing Three Important Food Safety Behaviors
}

Key Words: food safety, theory of planned behavior, employee attitudes

Author Information:

- Valerie K. Pilling, Ph.D., Research Associate in Psychology, Kansas State University; 492

Bluemont Hall, Kansas State University, Manhattan, KS, 66506; 785-532-6850; 785-532-5401 (fax); vpilling@ksu.edu.

- Laura A. Brannon, Ph.D., Associate Professor of Psychology, Kansas State University; 492

Bluemont Hall, Kansas State University, Manhattan, KS, 66506; 785-532-0604; 785-532-5401 (fax); lbrannon@ksu.edu.

- Carol W. Shanklin, Ph.D., R.D., Interim Dean of the Graduate School, Kansas State University; 103 Fairchild Hall, Kansas State University, Manhattan, KS, 66506; 785-532-6191; 785-532-2983 (fax); shanklin@ksu.edu.

- Amber D. Howells, M.S., R.D., Research Associate in Hotel, Restaurant, Institution Management \& Dietetics, Kansas State University; 104 Justin Hall, Kansas State University, Manhattan, KS, 66506; 785-532-5521; 785-532-5522 (fax); amberkstate@yahoo.com.

- Kevin R. Roberts, Ph.D., Assistant Professor in Hotel, Restaurant, Institution Management \& Dietetics, Kansas State University; 104 Justin Hall, Kansas State University, Manhattan, KS, 66506; 785-532-2399; 785-532-5522 (fax); kevrob@ksu.edu.

Corresponding Author: Carol W. Shanklin, 103 Fairchild Hall, Kansas State University, Manhattan, KS, 66506; 785-532-6191; 785-532-2983 (fax); shanklin@ksu.edu. 
Identifying Specific Beliefs to Target to Improve Restaurant Employees’ Intentions for Performing Three Important Food Safety Behaviors

\author{
Funding Disclosure
}

This project was partially funded through a grant from the National Integrated Food Safety Initiative (Grant No. 2004-51110-02170) of the Cooperative State Research, Education, and Extension Service, U.S. Department of Agriculture. 


\title{
Identifying Specific Beliefs to Target to Improve Restaurant Employees’ Intentions for Performing Three Important Food Safety Behaviors
}

\begin{abstract}
Current national food safety training programs appear ineffective at improving food safety practices in foodservice operations given the substantial number of Americans affected by foodborne illnesses after eating in restaurants each year. The Theory of Planned Behavior (TpB) was used to identify important beliefs that may be targeted to improve foodservice employees' intentions for three food safety behaviors that have the most substantial impact on public health: handwashing, using thermometers, and proper handling of food contact surfaces. In a crosssectional design, foodservice employees $(n=190)$ across three midwestern states completed a survey assessing TpB components and knowledge for the three food safety behaviors. Multiple regression analyses were performed on the $\mathrm{TpB}$ components for each behavior. Independentsamples t-tests identified TpB beliefs that discriminated between participants who absolutely intend to perform the behaviors and those with lower intention. Employees' attitudes were the one consistent predictor of intentions for performing all three behaviors. However, a unique combination of important predictors existed for each separate behavior. Interventions for improving employees' behavioral intentions for food safety should focus on TpB components that predict intentions for each behavior and should bring all employees' beliefs in line with those of the employees who already intend to perform the food safety behaviors. Registered dietitians, dietetic technicians registered, and foodservice managers can use these results to enhance training sessions and motivational programs to improve employees' food safety behaviors. Results also assist these professionals in recognizing their responsibility for enforcing and providing adequate resources for proper food safety behaviors.
\end{abstract}




\section{Identifying Specific Beliefs to Target to Improve Restaurant Employees’ Intentions for Performing Three Important Food Safety Behaviors}

Reducing foodborne illnesses is a public health priority $(1,2)$. The American Dietetic Association identified a safe food supply as a research priority (3). Annually in the United States, approximately 76 million foodborne illnesses cause 325,000 hospitalizations, 5,000 deaths (4), and costs between $\$ 10$ and $\$ 38$ billion (5).

Food consumption in restaurants contributes significantly to foodborne illnesses (6-8). Registered dietitians (RDs), dietetic technicians registered (DTRs), and foodservice managers and employees need to be aware of food safety issues to protect public health (6). The three most significant contributors to foodborne illnesses in restaurants include time/temperature abuse, personal hygiene, and cross contamination (1).

Food safety training attempts to improve employees' food safety practices. Training increases knowledge (6) and improves attitudes for food safety $(9,10)$, but rarely improves behavior (11-15). Food safety trainers, including RDs and DTRs, must identify strategies to minimize the gap between knowledge and action. "Belief facilitators" must be addressed to change improper food handling behaviors (16). Factors influencing proper food handling practices include time pressures, resources, education/training, and negative consequences (1719).

\section{The Theory of Planned Behavior}

The Theory of Planned Behavior $(\mathrm{TpB}, 20)$ allows the identification of influences on behavior in order to predict and change behavior. The theory contends behavior is most proximally predicted by behavioral intention, if the person has control over performing it. Further, behavioral intention is predicted from three antecedents: attitudes about the behavior, 
perceptions of important others' approval of performing the behavior (subjective norms), and perceived control over performing the behavior.

The $\mathrm{TpB}$ has been used to understand the antecedents of many health- and work-related behaviors (21-34). When specific antecedents are identified as significant predictors of intention, interventions are designed to influence the antecedents as a way to influence intention, and thus behavior (e.g., 26, 35-39).

This study explored which components of the Theory of Planned Behavior are significant predictors of intentions to perform three food safety behaviors related to the most common contributors to foodborne illness: handwashing, using thermometers, and sanitizing work surfaces $(1,40,41)$. Further, according to the Transtheoretical model (42), a difference exists between people who absolutely intend to perform a behavior (i.e., those who score a maximum intention score) and those who are inclined to perform it, but not firmly committed (i.e., those with less than a maximum intention score). Therefore, it is important to determine how employees with absolute intention to perform the behaviors and those with less intention differ in their beliefs about the behaviors. The study also identifies specific beliefs held by restaurant employees that can be targeted in interventions promoting food safety.

Methods

\section{Pilot Study}

The questionnaire was pilot tested with local foodservice employees $(n=37)$. Internal reliability estimates of the direct components of the $\mathrm{TpB}$ ranged between 0.65 and 0.90 .

\section{Main Study}

One-hundred ninety foodservice employees within a 300-mile radius of a midwestern university participated in the cross-sectional study. Between May, 2005 and July, 2006, 
participants were recruited through calling randomly selected restaurants in the directory or a list of licensed food establishments provided by the state licensing agency. Restaurant managers allowed employees to participate in exchange for free food safety training at a later time. Only employees whose jobs directly involved food preparation tasks could participate. Each participant completed a self-administered TpB questionnaire in English or Spanish. The cover page stated that the research was attempting to improve food safety and described the rights of the participants and informed consent. Kansas State University's Institutional Review Board approved the research protocol.

The questionnaire contained three sections. The first section was a food safety knowledge assessment designed by the researchers containing 54 true/false questions (18 per behavior). The second section assessed the $\mathrm{TpB}$ components. The final section contained demographic items.

The TpB section assessed attitudes, subjective norms, perceived control, and intention for the behaviors. The definitions of the three behaviors were presented to participants as in Table 1 . The questionnaire contained direct measures of attitude, such as "For me to properly wash my hands at work on a regular basis is" $(1=$ extremely bad, $7=$ extremely good $)$. One indirect attitude pair for handwashing was "Properly washing my hands at work on a regular basis will decrease the likelihood that people will get sick" ( $1=$ extremely unlikely, $7=$ extremely likely $)$ and "For me to decrease the likelihood that people will get sick is" $(-3=$ extremely bad, $3=$ extremely good).

The questionnaire included direct subjective norms questions. An example for using thermometers was "Most people whose opinions I value would approve of my using a thermometer to properly check the temperature of food $(1=$ strongly disagree, $7=$ strongly 
agree). One indirect subjective norms pair of items was "My co-workers think that I should use a thermometer to check the temperature of food at work" $(-3=$ extremely unlikely, $3=$ extremely likely), and "Generally speaking, how much do you want to do what your co-workers think you should do?" $(1=$ not at all, $7=$ very much $)$.

The questionnaire contained direct perceived control beliefs, such as "For me to properly wash my hands at work on a regular basis is" ( $1=$ extremely difficult, $7=$ extremely easy). One pair of items for assessing indirect perceived control beliefs was "How often does not having enough time affect you properly washing your hands at work?” $(1=$ very rarely, $7=$ very frequently) and "Not having enough time would make it more difficult for me to properly wash my hands at work on a regular basis" (-3 = strongly disagree, $3=$ strongly agree $)$.

Intention was measured only directly for each behavior with items like "I plan to properly handle food and work surfaces at work" ( $1=$ strongly disagree, $7=$ strongly agree $)$ and "I intend to use a thermometer to properly check the temperature of food" $(1=$ strongly disagree, $7=$ strongly agree). Participants completed TpB items for all three behaviors. This section was counterbalanced to avoid order effects, and it contained 150 items (approximately 50 per behavior).

Statistical Analysis

The data were analyzed with SPSS for Windows (version 12.0, 2004, SPSS Inc., Chicago, IL). Direct TpB component scores are means of the direct items for each component, while indirect $\mathrm{TpB}$ component scores are sums of the products of indirect item pairs.

Frequencies were run on gender, and descriptive statistics were calculated for age and years of working experience. Multiple linear regression analyses were conducted to test the model. Independent-sample t-tests were conducted to identify the indirect $\mathrm{TpB}$ beliefs discriminating 
between employees who absolutely intend to perform the behaviors and those with less intention. All significance levels were set at $p<.05$.

Results

Participants

Of 190 participants, $68.3 \%$ and $31.7 \%$ were male and female, respectively. Participants' age averaged 28.8 years, but ranged from 15 to 79 years. Participants averaged 7.5 years foodservice experience. Of 1,298 restaurants contacted, 31 managers agreed to participate. Of 211 eligible employees at participating restaurants, 190 employees completed the survey, for a response rate of $90 \%$.

Analyses of Direct TpB Measures

Three multiple linear regressions were performed to evaluate the TpB model for each behavior. Intentions to perform the behaviors were predicted from direct attitudes, subjective norms, perceived control, and knowledge of the behaviors.

Attitudes were the only consistent significant predictor for the behaviors, though there was a unique combination of predictors for each behavior (Table 2). Intention for handwashing was significantly predicted by attitudes and perceived control $(p<.001)$. The predictors of intention for using thermometers were attitudes, subjective norms, and perceived control $(p<$ .001). Intention for sanitizing surfaces was predicted by subjective norms and attitudes $(p<$ $.001)$.

Beliefs Discriminating Between Absolute Intenders and Lower Intenders

Independent-sample t-tests identified indirect beliefs discriminating between employees who absolutely intend to perform the behaviors and those with lower intention (Table 3). 
Attitudes. For each behavior, participants with lower intentions had less positive attitudes than absolute intenders (all $p$ 's $<.001$ ). For all behaviors, participants with lower intentions were less likely to think that doing so would decrease the likelihood that people will get sick or help keep customers satisfied. Additionally for handwashing and for sanitizing surfaces, lower intenders were less likely to think that performing the behaviors would reduce the spread of "germs" or keep the working environment clean. Further, for sanitizing surfaces, participants with lower intention were less likely to think that doing so would protect the restaurant from lawsuits. For using thermometers, lower intenders were less likely to think doing so would ensure high quality food, less likely to recognize using a thermometer will give them the (incorrect) idea that the food is safe even if they did it wrong, and more likely to think doing so would take a lot of time.

Subjective Norms. For each behavior, employees with less intention to perform the behaviors had less positive subjective norms than absolute intenders (all $p$ 's $<.001$ ). In all cases, lower intenders were less likely to think performing the behaviors would be supported by their boss, coworkers, customers, and health inspector.

Perceived Control. For all behaviors, there were no significant differences in overall perceptions of control between absolute intenders and those lower in intention (all $p$ 's $>.05$ ). However, for sanitizing surfaces and using thermometers, those with lower intention were more likely to think not having proper training makes it difficult to do so. Further, compared to absolute intenders, those with less intention to use thermometers were more likely to agree not having reminder signs about correct food temperatures and not having enough thermometers available make it difficult to do so. 


\section{Knowledge}

Participants averaged 42.73 of 54 possible points $(\mathrm{SD}=5.02 ; 79.13 \%)$ on the overall knowledge assessment. Knowledge scores were not significant predictors of intention for any behavior. Absolute intenders did not differ significantly from lower intenders in knowledge scores.

\section{Discussion}

The Theory of Planned Behavior examined how restaurant employees' attitudes, subjective norms, and perceived control influence intentions for performing food safety behaviors. Specific beliefs discriminating between employees who already intend to perform the behavior and those who do not were identified. These beliefs can be targeted in interventions to improve compliance with safety guidelines. While past studies identified factors that influence food safety behaviors $(9,16-19)$, no previous research explored the relative importance of such factors for multiple behaviors.

Importance of Attitudes across Food Safety Behaviors. Attitudes were the one consistent significant predictor for all behaviors. This result is consistent with research finding that restaurant operators with positive food safety attitudes were more likely to practice proper practices (9), but is less consistent with research conducted in schools (43) and assisted living facilities (44) where foodservice employees' food safety attitudes were favorable yet many food safety practices were not implemented. Foodservice managers, RDs, and DTRs should offer training that targets employees' attitudes toward specific behaviors, and toward food safety in general. Training should emphasize positive outcomes of performing the behaviors, stressing positive outcomes (e.g., decreasing the likelihood people get sick) far outweigh potential negative outcomes (e.g., taking time). Foodservice managers, RDs, and DTRs could implement 
motivational programs encouraging employees to follow food safety guidelines (e.g., monthly bonuses for employees demonstrating excellent safety behaviors, fact sheets included in employee paychecks focusing on the importance of food safety).

Variability of Predictors across Food Safety Behaviors. Although employees' attitudes consistently influence intentions for performing food safety practices at work, each behavior had a unique combination of significant predictors. While finding ways to improve employees' attitudes related to all three behaviors would be beneficial, it would also help to improve employees' subjective norms about using thermometers and sanitizing surfaces. To do so, RDs, DTRs, and foodservice managers should serve as good role models by following proper food safety practices themselves. They should also monitor employees' behavior and provide positive feedback to employees performing proper safety practices.

It would also be helpful for RDs, DTRs, and foodservice managers to improve employees' perceptions of control over handwashing and using thermometers. They must ensure employees have necessary resources for properly performing behaviors (e.g., hand soap, paper towels, and thermometers) and should develop and incorporate standard operating procedures into employees' daily routines to eliminate employees' concerns about time requirements for performing the procedures.

Providing Knowledge is Not Sufficient. Knowledge of food safety behaviors was never a significant predictor of intention to perform the behaviors. Providing employees with training that does not target attitudes, subjective norms, and perceptions of control may not improve intentions (and ultimately behavior) for performing the behaviors. This finding is somewhat inconsistent with research reporting schools with foodservice managers and employees with food safety certificates have higher food safety compliance scores (43) and restaurants with managers 
with food safety training have better inspection scores (45). Foodservice managers, RDs, and DTRs should create educational programs focusing on improving employee attitudes, subjective norms, and perceived control for food safety.

Importance of Targeting Specific Beliefs. This study identified specific beliefs underlying employees' attitudes, subjective norms, and perceived control discriminating between employees who absolutely intend to perform the behaviors and those with less intention. These beliefs can be targeted in educational interventions to improve the significant predictors of intention for the behaviors (i.e., attitudes, subjective norms, or perceived control). Bringing all employees' beliefs in line with those who already intend to perform the behaviors should lead to better operation-wide intentions and eventually compliance with the behaviors. See Table 3 for complete list of beliefs to target. To improve attitudes, trainers should target beliefs that were found to discriminate between employees who absolutely intend to perform the behaviors and those with lower intention (e.g., they should stress doing the behaviors reduces the number of people who get sick, reduces the spread of microorganisms, and keeps the customers satisfied). To improve subjective norms, trainers should stress that bosses, co-workers, customers, and health inspectors want them to properly perform the behaviors. Perceived control can be improved by supplying adequate resources and reminding employees to perform the behaviors. Using these results, RDs, DTRs, and managers can improve employee attitudes, subjective norms, and perceived control for three important safety behaviors, which should improve the effectiveness of training.

Limitations. Results indicate that foodservice employees have high intentions for performing the food safety behaviors. This is surprising given intentions are considered the most proximal predictor of behavior. Research consistently shows that few employees are 
practicing proper food safety behaviors $(1,46)$. It is possible that these numbers are inflated indications of intentions due to the nature of self-reporting. While this possibility is noted, this should not cause problems with the results. It is still meaningful to make a distinction between absolute intenders and employees with lower intentions to perform the behaviors. Distinctions like these are often made when investigating health behavior change (42).

Although 1,298 restaurants were contacted, only 31 restaurants began participating. During recruitment, restaurant managers were asked to participate in a three-year study, which involved having their employees complete the survey AND allowing researchers into their kitchens multiple times to observe employee behaviors. Due to the long timeframe and intrusiveness of data collection, few restaurant managers were willing to participate. Most managers declining participation did not have time to make such a commitment. The authors speculate that because the manager decided whether or not to participate, the actual employees who participated did not differ significantly from employees whose managers were contacted but were not given the option to participate. There is no reason to assume that participation was an indication of employees' personal interest in food safety. It is likely that many non-participants would have been willing to participate if given the opportunity by the manager. Further, employees were not forced to participate even if the manager gave permission. However, because no data was collected from non-participants, the similarity between the participating and non-participating employees cannot be determined. Future research should replicate this study with foodservice employees who are approached individually and independently of an operation for participation.

Directions for Future Research. This study provides results on the relative importance of predictors of intention for three food safety behaviors with significant impact on public health. 
Although intentions are the best predictors of behavior, it would be interesting to obtain measures of behavior and relate those to intentions. This would provide a more complete understanding of foodservice employees' beliefs and actions related to food safety. Behavioral observations would allow identifying behaviors in need of the most improvement, and the Theory of Planned Behavior would offer insights for addressing these concerns.

This research investigated food safety behaviors among employees in restaurants. Future research could investigate behaviors using the $\mathrm{TpB}$ in other areas where RDs and DTRs work such as schools, daycare, healthcare, and senior living facilities. Research could determine if foodservice employees' attitudes and intentions toward safety behaviors differ based on the populations they serve. Research should investigate employees who work with populations at higher risk for foodborne illnesses (e.g., very young children, pregnant women, elderly, those with compromised immune systems). Research indicates that foodservice employees in schools, assisted living, and long-term care facilities have favorable knowledge and attitudes about food safety, yet they too fail to take action $(44,47)$. Research must be conducted regarding food safety intentions and behaviors in facilities serving at-risk populations.

Conclusions. Registered dietitians work in many settings with foodservice employees, including consultant and management roles in restaurants. Foodservice employees often work in a variety of foodservice sectors throughout their careers, so it is likely that RDs work with current or former restaurant employees. Registered dietitians are an integral part of the management team that educates employees on food safety. While emphasis should be placed on training, it is also important to educate employees regarding positive outcomes of food safety such as decreasing patrons' risk of foodborne illness, reducing the spread of microorganisms, and keeping the work environment clean. It is essential for RDs to monitor employees' safety 
practices and to serve as good role models by practicing correct safety behaviors themselves. Improving compliance with food safety is important to reduce foodborne illnesses. 


\section{References}

1. Food and Drug Administration. FDA report on the occurrence of foodborne illness risk factors in selected institutional foodservice, restaurant, and retail food store facility types. 2004. Available at: http://www.cfsan.fda.gov/ acrobat/retrsk2.pdf. Accessed June 25, 2006.

2. United States Department of Health and Human Services. Healthy people 2010:

Understanding and improving health. $2^{\text {nd }}$ ed. Washington, DC: U.S. Government Printing Office; 2000. Available at:

http://www.healthypeople.gov/Document/tableofcontents.htm\#volume1. Accessed November 29, 2006.

3. Castellanos VH, Myers EF, Shanklin CW. The ADA's research priorities contribute to a bright future for dietetics professionals. J Am Diet Assoc. 2004;104:678-681.

4. Centers for Disease Control and Prevention. Foodborne illness: Frequently asked questions. 2005. Available at:

http://www.cdc.gov/ncidod/dbmd/dieaseinfo/files/foodborne_illness_FAQ.pdf. Accessed October 17, 2006.

5. Food and Drug Administration. Food Code. 2005. Available at: http://www.cfsan.fda.gov/ dms/fc05-toc.html. Accessed November 14, 2006.

6. Lynch RA, Elledge BL, Griffith CC, Boatright DJ. A comparison of food safety knowledge among restaurant managers, by source of training and experience, in Oklahoma County, Oklahoma. Journal of Environmental Health. 2003;66(2):9-14. 
7. Centers for Disease Control and Prevention. Preliminary FoodNet data on the incidence of infection with pathogens transmitted commonly through food - 10 states, United States, 2005. MMWR Morb Mortal Wkly Rep. 2006; 55(14). Available at:

http://www.cdc.gov/mmwr/preview/mmwrhtml/mm5514a2.htm?s_cid=mm5514a2_e. Accessed November 29, 2006.

8. Harrington, RE. The role of employees in the spread of foodborne disease: Food industry views of the problem and coping strategies. Dairy, Food, and Environmental Sanitation. $1992 ; 12: 62-63$.

9. Cochran-Yantis D, Belo P, Giampaoli J, McProud L, Everly V, Gans J. Attitudes and knowledge of food safety among Santa Clara County, California restaurant operators. Journal of Foodservice Systems. 1996;9:117-128.

10. Edwards ZM, Takeuchi MT, Hillers VN, McCurdy SM, Edlefsen M. Use of behavioral change theories in development of educational materials to promote food thermometer use. Food Protection Trends. 2006;26,82-88.

11. Cohen E, Reichel A, Schwartz Z. The efficacy of an in-house training program: Statistical measurement and practical conclusions. Journal of Hospitality \& Tourism Research. $2001 ; 25(1): 5-16$.

12. Kneller P, Bierma T. Foodservice certification: Measuring the effectiveness of a state program. Journal of Environmental Health. 1990;52(5):292-294.

13. Speer SC, Kane BE. Certification for foodservice managers: A survey of current opinion. Journal of Food Protection. 1990;53:269-274.

14. Bryan FL. Risks of practices, procedures, and processes that lead to outbreaks of foodborne diseases. Journal of Food Protection. 1988;51:663-673. 
15. Li-Cohen AE, Klenk M, Nicholson Y, Harwood J, Bruhn CM. Refining consumer safe handling educational materials through focus groups. Dairy, Food, and Environmental Sanitation. 2002;22:539-551.

16. Boone K, Penner K, Gordon JC, Remig V, Harvey L, Clark T. Common themes of safe foodhandling behavior among mature adults. Food Protection Trends. 2005;25,706-711.

17. Brannon, LA, Pilling, VK, Roberts, KR, Shanklin, CW, Howells, AD. Appreciation of food safety practices based on level of experience. Journal of Foodservice Business Research. in press.

18. Green LR, Selman C. Factors impacting food workers' and managers'safe food preparation practices: A qualitative study. Food Protection Trends. 2005;25:981-990.

19. Pilling VK, Brannon LA, Roberts KR, Shanklin CW, Howells AD. Using the Theory of Planned Behavior to elicit restaurant employee beliefs about food safety: Using surveys versus focus groups. Journal of Foodservice Business Research. in press.

20. Ajzen I. The theory of planned behavior. Organizational Behavior and Human Decision Processes. 1991;50:179-211.

21. Astrom AN, Mwangosi IE. Teacher's intention to provide dietary counseling in Tanzanian primary schools. American Journal of Health Behavior. 2000;24:281-289.

22. Boissonneault E, Godin G. The prediction of intention to smoke only in designated work site areas. Journal of Occupational Medicine. 1990;32:621-624.

23. Boudreau F, Godin G, Pineau R, Bradet R. Health risk appraisal in an occupational setting and its impact on exercise behavior. J Occup Environ Med. 1995;37:1145-1150. 
24. Coleman GJ, McGregor M, Hemsworth PH, Boyce J, Dowling S. The relationship between beliefs, attitudes and observed behaviours of abattoir personnel in the pig industry. Applied Animal Behaviour Science. 2003;82:189-200.

25. Flannery BL, May DR. Environmental ethical decision making in the U.S. metal-finishing industry. Academy of Management Journal. 2000;43:642-662.

26. Godin G, Naccache H, Morel S, Ebacher M. Determinants of nurses' adherence to Universal Precautions for venipunctures. Am J Infect Control. 2000;28:359-364.

27. Harrison DA, Liska LZ. Promoting regular exercise in organizational fitness programs: Health-related differences in motivational building blocks. Personnel Psychology. $1994 ; 47: 47-71$.

28. James AS, Tripp MK, Parcel GS, Sweeney A, Gritz ER. Psychological correlates of sunprotective practices of preschool staff toward their students. Health Education Research. 2002;17:305-314.

29. Jenner EA, Watson PWB, Miller L, Jones F, Scott GM. Explaining hand hygiene practice: An extended application of the theory of planned behaviour. Psychology, Health, and Medicine. 2002;7:311-326.

30. Martin JJ, Hodges-Kulinna P, Eklund RC, Reed B. Determinants of teachers' intentions to teach physically active physical education classes. Journal of Teaching in Physical Education. 2001;20:129-143.

31. O’Boyle CA, Henly SJ, Larson E. Understanding adherence to hand hygiene recommendations: The theory of planned behavior. Am J Infect Control. 2001;29:352360. 
32. Randall DM, Gibson AM. Ethical decision-making in the medical profession: An application of the theory of planned behavior. Journal of Business Ethics. 1991;10:111-122.

33. Sheeran P, Silverman M. Evaluation of three interventions to promote workplace health and safety: Evidence for the utility of implementation intentions. Soc Sci Med. 2003;56:21532163.

34. Sparks P, Shepherd R, Frewer LJ. Assessing and structuring attitudes toward the use of gene technology in food production: The role of perceived ethical obligation. Basic and Applied Social Psychology. 1995;16:267-285.

35. Brubaker RG, Fowler C. Encouraging college males to perform testicular self-examination: Evaluation of a persuasive message based on the revised theory of reasoned action. Journal of Applied Social Psychology. 1990;17:1411-1422.

36. Jemmott JB, Jemmott LS, Fong GT. Abstinence and safer sex HIV riskreduction interventions for African American adolescents. JAMA. 1998;279:1529-1536.

37. Murphy WG, Brubaker RG. Effects of a brief theory-based intervention on the practice of testicular self-examination by high school males. J Sch Health. 1990;60:459-462.

38. Rodgers WM, Brawley LR. Using both self-efficacy theory and the theory of planned behavior to discriminate adherers and dropouts from structured programs. Journal of Applied Sport Psychology. 1993;5:195-206.

39. Sheehan M, Schonfeld C, Ballard R, Schofield F, Najman J, Siskind V. A three year outcome evaluation of a theory based drink driving education program. J Drug Educ. 1996;26:295-312.

40. Collins JE. Impact of changing lifestyles on the emergence/reemergence of foodborne pathogens. Emerg Infect Dis. 1997;3:471-479. 
41. National Restaurant Association Educational Foundation. ServSafe Coursebook (3rd ed.). Chicago, IL: National Restaurant Association Educational Foundation; 2004.

42. Prochaska JO, DiClemente CC. Stages and processes of self-change of smoking: Toward an integrative model of change. J Consult Clin Psychol. 1983;51:390-395.

43. Henroid D, Sneed J. Readiness to implement Hazard Analysis and Critical Control Point (HACCP) systems in Iowa schools. J Am Diet Assoc. 2004;104(2):180-185.

44. Sneed J, Strohbehn C, Gilmore SA. Food safety practices and readiness to implement HACCP programs in assisted-living facilities in Iowa. J Am Diet Assoc. 2004;104(11):1678-1683.

45. Cotterchio M, Gunn J, Coffill T, Tormey P, Barry A. Effect of a Manager Training Program on Sanitary Conditions in Restaurants. Public Health Rep. 1998;113:353-358.

46. Food and Drug Administration. Report of the FDA retail food program database of foodborne illness risk factors. 2000. Available at: http://vm.cfsan.fda.gov/ dms/retrsk.html. Accessed July 1, 2007.

47. Strohbehn CH, Gilmore SA, Sneed J. Food safety practices and HACCP implementation: Perceptions of registered dietitians and dietary managers. J Am Diet Assoc. 2004;104(11):1692-1699. 
Table 1. Food Safety Definitions Presented to Participants

PROPERLY HANDLING FOOD AND WORK SURFACES:

- Not allowing raw food to come into contact with ready-to-eat foods.

- Cleaning and sanitizing all food contact surfaces (hands/gloves, countertops, cutting surfaces, equipment, dishes \& utensils) between each use.

- Cleaning and sanitizing all food contact surfaces when switching from one food preparation task to another.

USING A THERMOMETER TO CHECK THE TEMPERATURE OF FOOD:

- At the completion of cooking (various temperatures)

- At the completion of reheating (to 165 degrees)

- To ensure that food stored on the hot line is at least 135 degrees

- To ensure that food stored on the cold line is 41 degrees or less

HANDWASHING:

- Washing with soap and hot water for 20 seconds

- Drying (with an air dryer or single use paper towels)

- Washing hands before work

- Washing hands before putting on gloves

- Washing hands when food preparation tasks are interrupted or changed

- Washing hands whenever they come in contact with something that might have germs (food, the bathroom, coughing, or touching body parts) 
Table 2. Means, Standard Deviations, and Regression Beta Weights of Theory of Planned Behavior Components for Three Food Safety Behaviors ( $\mathrm{n}=190)$

\begin{tabular}{|c|c|c|c|c|c|c|c|c|c|c|}
\hline & \multicolumn{2}{|c|}{ Attitudes } & \multicolumn{2}{|c|}{ Subjective Norms } & \multicolumn{2}{|c|}{ Perceived Control } & \multicolumn{2}{|c|}{ Knowledge } & \multicolumn{2}{|c|}{ Intention } \\
\hline Behavior & Mean \pm SD & $\beta$ & Mean \pm SD & $\beta$ & Mean \pm SD & $\beta$ & Mean \pm SD & $\beta$ & Mean $\pm \mathrm{SD}$ & $\mathrm{R}^{2}$ \\
\hline Handwashing & $6.60 \pm 0.70$ & $0.50 * * *$ & $6.26 \pm 1.19$ & -0.01 & $6.57 \pm 0.79$ & $0.37 * *$ & $15.22 \pm 2.01$ & 0.02 & $6.48 \pm 0.96$ & 0.39 \\
\hline Using Thermometers & $6.42 \pm 0.78$ & $0.53 * * *$ & $5.95 \pm 1.22$ & $0.34 * * *$ & $6.50 \pm 0.80$ & $0.26 * *$ & $13.74 \pm 2.52$ & -0.03 & $6.20 \pm 1.16$ & 0.60 \\
\hline Sanitizing Surfaces & $6.59 \pm 0.76$ & $0.32 *$ & $6.26 \pm 1.25$ & $0.48^{* * *}$ & $6.48 \pm 0.85$ & 0.07 & $13.77 \pm 1.75$ & 0.02 & $6.57 \pm 1.15$ & 0.54 \\
\hline
\end{tabular}

Note. $* \mathrm{p}<.05, * * \mathrm{p}<.01, * * * \mathrm{p}<.001$.

Note. SD indicates standard deviation, $\beta$ indicates the regression beta weight, and $\mathrm{R}^{2}$ indicates multiple $\mathrm{R}$ square.

Note. The attitudes, subjective norms, perceived control, and intention items were measured on Likert-style scales ranging from 1 to 7 . Higher numbers indicate more positive attitudes or subjective norms, or more perceived control or intention. Knowledge scores had a possible range from 0 to 18 , with higher scores indicating more knowledge. 
Table 3. Means and Standard Deviations of Indirect Beliefs Discriminating Between Employees with Absolute Intention to Perform the Food Safety Behaviors and Employees with Lower Intention to Perform the Behaviors $(n=190)$

\begin{tabular}{|c|c|c|c|c|c|c|}
\hline \multirow[b]{3}{*}{ Indirect Beliefs } & \multicolumn{6}{|c|}{ Food Safety Behavior } \\
\hline & \multicolumn{2}{|c|}{ Handwashing } & \multicolumn{2}{|c|}{ Using Thermometers } & \multicolumn{2}{|c|}{ Sanitizing Surfaces } \\
\hline & $\begin{array}{l}\text { Lower } \\
\text { Intender }\end{array}$ & $\begin{array}{l}\text { Absolute } \\
\text { Intenders }\end{array}$ & $\begin{array}{l}\text { Lower } \\
\text { Intenders }\end{array}$ & $\begin{array}{l}\text { Absolute } \\
\text { Intenders }\end{array}$ & $\begin{array}{l}\text { Lower } \\
\text { Intenders }\end{array}$ & $\begin{array}{l}\text { Absolute } \\
\text { Intenders }\end{array}$ \\
\hline & \multicolumn{6}{|c|}{ Mean \pm Standard Deviation } \\
\hline Overall Attitudes ${ }^{\mathrm{a}}$ & $44.79 \pm 44.47$ & $78.08 \pm 16.22 * * *$ & $24.11 \pm 25.99$ & $42.93 \pm 26.66^{* * *}$ & $40.50 \pm 66.30$ & $96.22 \pm 24.54^{* * *}$ \\
\hline Decreases the likelihood that people will get sick & $12.11 \pm 12.93$ & $19.63 \pm 4.49^{* * *}$ & $13.11 \pm 10.20$ & $19.53 \pm 5.76^{* * *}$ & $9.03 \pm 13.08$ & $18.86 \pm 6.29 * * *$ \\
\hline Reduces the spread of "germs" & $12.68 \pm 12.22$ & $19.92 \pm 4.07^{* * *}$ & $-11.59 \pm 12.45$ & $-12.78 \pm 14.86$ & $8.29 \pm 13.51$ & $19.11 \pm 6.15^{* * *}$ \\
\hline Keeps the customers satisfied & $11.65 \pm 11.41$ & $19.84 \pm 4.92 * * *$ & $13.52 \pm 9.15$ & $19.30 \pm 5.03^{* * *}$ & $8.53 \pm 13.51$ & $19.40 \pm 4.66^{* * *}$ \\
\hline Takes a lot of time & $-0.51 \pm 8.10$ & $1.31 \pm 8.17$ & $-3.41 \pm 7.66$ & $1.50 \pm 8.05^{* * *}$ & $-2.32 \pm 8.91$ & $0.16 \pm 7.93$ \\
\hline Keeps the work environment clean & $12.11 \pm 10.33$ & $19.37 \pm 4.30 * * *$ & & & $9.11 \pm 13.30$ & $19.49 \pm 4.70^{* * *}$ \\
\hline Ensures high food quality & & & $12.38 \pm 9.26$ & $19.89 \pm 4.12 * * *$ & & \\
\hline Gives the idea that food is safe even if done wrong & & & $-1.01 \pm 9.42$ & $-4.14 \pm 11.26^{*}$ & & \\
\hline Protects the restaurant from lawsuits & & & & & $7.87 \pm 14.01$ & $19.24 \pm 5.53 * * *$ \\
\hline Slows you down & $-2.79 \pm 6.89$ & $-2.09 \pm 4.73$ & & & & \\
\hline Overall Subjective Norms ${ }^{b}$ & $39.02 \pm 41.37$ & $71.70 \pm 23.02 * * *$ & $50.11 \pm 38.46$ & $70.63 \pm 25.71^{* * *}$ & $29.70 \pm 45.01$ & $68.82 \pm 24.91^{* * *}$ \\
\hline Boss & $11.96 \pm 11.99$ & $18.62 \pm 7.09 * * *$ & $7.22 \pm 12.73$ & $18.22 \pm 6.68^{* * *}$ & $7.05 \pm 13.47$ & $18.18 \pm 6.97 * * *$ \\
\hline Coworkers & $7.23 \pm 11.89$ & $15.49 \pm 8.99 * * *$ & $3.27 \pm 11.06$ & $15.16 \pm 9.50^{* * *}$ & $5.08 \pm 10.90$ & $15.01 \pm 8.70^{* * *}$ \\
\hline Customers & $9.23 \pm 13.26$ & $18.27 \pm 8.25^{* * *}$ & $7.91 \pm 12.39$ & $17.94 \pm 7.13^{* * *}$ & $8.30 \pm 12.10$ & $18.06 \pm 6.39 * * *$ \\
\hline Health Inspector & $10.74 \pm 13.74$ & $19.39 \pm 6.32 * * *$ & $12.23 \pm 12.46$ & $18.92 \pm 7.68^{* * *}$ & $9.61 \pm 12.74$ & $17.64 \pm 8.96^{* * *}$ \\
\hline
\end{tabular}


Overall Perceived Control $^{\mathrm{c}}$

Not having reminder signs

Not having proper training

Not having enough resources (e.g., sinks,

thermometers, sanitizers, etc)

Not having reminders from manager

Not having reminders from other employees

Not having enough time

Not having resources in convenient location

$\begin{array}{llllll}1.46 \pm 31.38 & 1.50 \pm 29.56 & -7.48 \pm 2.18 & -17.85 \pm 36.99 & -1.84 \pm 26.68 & -7.10 \pm 26.67 \\ 1.26 \pm 6.50 & 0.98 \pm 6.46 & 0.85 \pm 7.91 & -2.93 \pm 8.87^{* *} & 0.68 \pm 6.44 & 0.57 \pm 6.58 \\ -0.16 \pm 6.47 & -0.88 \pm 5.87 & -2.54 \pm 7.01 & -4.79 \pm 7.56^{*} & -0.58 \pm 8.39 & -3.32 \pm 6.21^{*} \\ -1.23 \pm 6.54 & -0.91 \pm 5.51 & -2.37 \pm 8.21 & -4.85 \pm 7.68^{*} & -2.11 \pm 7.47 & -3.01 \pm 5.89 \\ 2.69 \pm 6.21 & 2.47 \pm 7.11 & 0.77 \pm 7.03 & -1.27 \pm 7.49 & 2.21 \pm 5.44 & 1.48 \pm 6.72 \\ 1.72 \pm 5.47 & 1.40 \pm 5.97 & & & & -2.16 \pm 7.09 \\ -0.76 \pm 6.80 & 0.53 \pm 4.86 & -1.34 \pm 7.99 & -0.52 \pm 7.34 & -0.91 \pm 5.79 \\ -2.15 \pm 5.47 & -2.12 \pm 6.40 & -2.71 \pm 7.00 & -3.35 \pm 7.70 & -0.13 \pm 6.58 & -1.89 \pm 6.13 \\ \end{array}$

Note. $* \mathrm{p}<.05, * * \mathrm{p}<.01, * * * \mathrm{p}<.001$.

Note. The Absolute Intender category represents employees with absolute intention to perform the food safety behavior and the Lower Intender category represents employees with less than absolute intention to perform the food safety behavior.

Note. The possible range of scores for all individual indirect belief entries (all except those labeled "Overall”) is -21 to 21 , with a higher number indicating a more positive belief.

\footnotetext{
${ }^{a}$ The possible range of values for overall attitude scores was -126 to +126 , with a higher number indicating a more positive attitude.

${ }^{b}$ The possible range of values for overall subjective norm scores was -84 to +84 , with a higher number indicating more positive subjective norms (that important others supported the performance of the behavior).

${ }^{\mathrm{c}}$ For handwashing, the possible range of overall perceived control scores was -147 to +147 , and for the behaviors using thermometers and sanitizing surfaces the possible range was -126 to 126 , with a higher number indicating more perceived control.
} 